\section{La insuficiencia de los códigos deontológicos brasileños}

\section{Façanha, Telma Rejane dos Santos}

Universidade de Brasília, Faculdade de Ciências da Saúde, Cátedra Unesco de Bioética, Programa de Pós-graduação em Bioética, Brasília/DF, Brasil.telmarejane68@gmail.com

\section{Garrafa, Volnei}

Universidade de Brasília, Centro Internacional de Bioética e Humanidades, Cátedra Unesco de Bioética, Programa de Pós-graduação em Bioética, Brasília/DF, Brasil.

PALAVRAS-ChAVE: Bioética. Códigos éticos. Salud pública.

Los códigos éticos pueden ser vistos como "marcas de una profesión" o como señales de que un grupo se organiza, reivindicando autoridad epistémica y moral, definiendo sus fronteras y por tanto sus relaciones con otros grupos, señalando una autorregulación, y declarando tanto lo que esa profesión cree que debe a los demás y lo que a su vez le es debido. De otro modo, los códigos son a menudo autógenos y exclusivos y pueden ser ciegos a las dimensiones sociales y políticas de la práctica profesional, ya que concentran más esfuerzos en el mantenimiento de los intereses de la profesión que en los intereses generales de la sociedad. Por tanto, es tiempo de que los códigos de ética profesional brasileños tengan más en cuenta los aspectos socio-políticos de la atención sanitaria, las funciones de todos los profesionales de la salud y la comprensión de que los resultados que los pacientes anhelan, forman parte de complejos sistemas de atención y cuidados. Esto no significa que los modelos de códigos deontológicos que siguen el referencial biomédico sean inaceptables, sino que son insuficientes para responder a los macroproblemas de salud de los países "periféricos". Así, tales códigos deben ser complementados con otros referenciales. Además, los referenciales que guían los códigos de ética profesionales del área de salud de modo general, se han mostrado incapaces para el análisis y juicio de los errores que causan daños a los pacientes y a la sociedad, ya que la atención de salud involucra no sólo aspectos biomédicos, sino también sociopolíticos y culturales, dentro de un contexto de pluralismo de valores morales. En este contexto, es fundamental expandir los referenciales que permean los códigos éticos profesionales en Brasil, de manera que el juicio de los deberes y obligaciones de los mismos no queden reducidos a una esfera hegemónica, en contextos sanitarios complejos, donde hay grandes desigualdades e incontables problemas sociales. Es sabido que en el transcurso de gran parte del siglo XX, las cuestiones éticas y deontológicas que permeaban las prácticas en el campo de la salud eran usualmente de naturaleza individual y biomédica. Hoy las situaciones que involucran la atención sanitaria han adquirido una nueva identidad pública. Un ejemplo regional y geopolítico que puede ser utilizado en este sentido es la construcción de las llamadas "Bioéticas Latino-americanas" que incorporan la ética biomédica. Pero ya no se limitan a ella las fronteras deontológicas propias y exclusivas de las relaciones entre profesionales y pacientes sino por el contrario, incorporan conceptos más amplios en su interpretación de "calidad de la vida humana". Entre las "Bioéticas Latino-americanas", se incluye la "Bioética de Intervención", que ofrece instrumentos teóricometodológicos útiles para el análisis de las cuestiones que involucran los daños causados a los pacientes. Esta "Bioética de Intervención" es una opción plausible, pues se expande evidentemente en un escenario global en el campo de la salud y aplicando categorías genuinas tales como responsabilidad, cuidado, solidaridad, compromiso, alteridad, tolerancia, y la prevención de posibles daños e iatrogenia frente a lo desconocido. Además plantea prudencia con respecto a los avances e innovaciones y protección de los socialmente excluídos, los más frágiles y los "sin ayuda". En este sentido, la "Bioética de Intervención" constituye una propuesta antihegemónica cuya fundamentación epistemológica va más allá de la visión vertical e individualizada propuesta por los códigos deontológicos del siglo XXI.

\section{REFERÊNCIAS}

[1] Pyrrho M, Prado MM, Cordón J, Garrafa V. Análise bioética do Código de Ética Odontológico brasileiro. Ciência \& Saúde Coletiva 2009; 14(5):1911-1918.

[2] Rivas-Muñoz F, Garrafa V, Feitosa S, Nascimento WF. Bioética de Intervención, interculturalidad y nocolonialidad. Saúde Soc. São Paulo 2015; 24(1):141-51.

[3] Soares FJP, Shimizu HE, Garrafa V. Código de Ética Médica brasileiro: limites deontológicos e bioéticos. Rev bioét. (Impr.) 2017; 25(2):244-54. 